\title{
Measuring metabolic fluxes in organs and tissues with single and multiple tracers
}

\section{By B. Crabtree and G. E. Lobley*, Division of Physiology, Rowett Research Institute, Bucksburn, Aberdeen AB2 $9 S B$}

The rates of metabolic pathways in vivo are frequently measured by using molecules labelled with either radioactive or stable isotopes. Such investigations usually involve administering only one labelled substance and, with large commercial species and man, are often additionally restricted to measuring fluxes in the whole animal. Although these relatively simple procedures have provided a bedrock of information, their limitations are well recognized. First, whole-animal fluxes do not provide information about the response of individual tissues and organs to various stimuli. This information usually requires invasive surgical procedures which, although becoming more common with advances in surgical techniques, are not yet routinely available. Second, the extensive transformations that occur between metabolites mean that single tracers often cannot provide accurate measurements of metabolic fluxes. For example, the 'crossover' of carbon atoms that occurs in the tricarboxylic acid cycle may lead to an overestimation of the oxidation of certain substrates and an underestimation of their contribution to gluconeogenesis if only a single ${ }^{14} \mathrm{C}$-labelled substrate is used (Weinman et al. 1957; Vinay et al. 1978; Katz \& Grunnet, 1979; Katz, 1985).

The general aim of this presentation is to show how metabolic fluxes can be measured by using isotopic tracers (radioactive or stable) either singly or in various combinations. Since it is impossible to cover the entire field of metabolism in a short review, we are focusing attention on cyclic processes. These provide relatively simple examples of the use of multiple tracers and may be of considerable energetic and hence nutritional importance (see Newsholme \& Crabtree, 1976; Newsholme, 1978).

Our discussions are based on simple algebraic models, since this is the best way of identifying and developing common principles and potential pitfalls. However, since we are concerned mainly with principles, we are confining attention to only the simplest experimental situation, in which tracers are administered continuously. This produces an isotopic steady-state in which the specific activities of both the tracer metabolite and many of its metabolic products reach 'constant' or 'plateau' values. Details of how to adapt the modelling to alternative experimental procedures, especially pulse (singleinjection) labelling, may be found in Shipley \& Clark (1972), Norwich (1977), Hetenyi (1981) and Young et al. (1987).

\section{Measuring cycling rates using a single label}

The modelling used here is based on that developed extensively by Katz and his colleagues (see Katz \& Rognstad, 1976; Katz \& Grunnet, 1979), in which an isotopic flux is related to its corresponding mass flux (i.e. reaction rate) by the equation:

isotopic flux of substrate $X$ to product $P=$ mass flux of $X$ to $P \times$ specific activity of $X$.

For radioactive isotopes the 'specific activity' is now referred to as specific radioactivity and represents the amount of tracer $\left(X^{*}\right)$ divided by the amount of unlabelled $X$ (tracee). For stable isotopes the 'specific activity' is the molar ratio, tracer:tracee, which is a simple function of the isotope enrichment or mol(atom) \% excess (see Tserng \& Kalhan, 1983a). Isotopic-flux equations may be written for the entire molecule, or for the individual atoms within that molecule (see Katz \& Grunnet, 1979).

*For reprints 


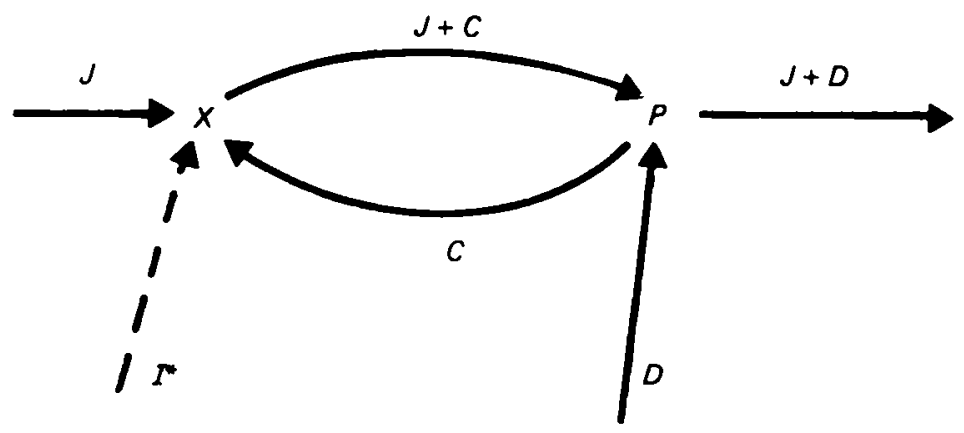

Fig. 1. Simple model of a metabolic cycle. $X$, substrate; $P$, product; $I^{*}$, (continuous) input of label; $C$, rate of cycling; $J$, net flux of $X$ to $P ; D$, any flux(es) diluting $P$ (these may be irreversible fluxes, as here, or an exchange of $P$ with a large unlabelled pool). This model may represent a single reversible reaction (e.g. transamination) or an 'energy-dissipating' cycle in which $X \rightarrow P$ and $P \rightarrow X$ are catalysed by distinct enzymes. If the label is added in tracer amounts, so that its mass flux is negligible compared with $J$,

$$
\begin{aligned}
& \text { isotopic flux to } X=I^{*}+C \times S_{P}, \\
& \text { isotopic flux from } X=(J+C) \times S_{X},
\end{aligned}
$$

where $S_{X}$ and $S_{P}$ are the specific activities of $X$ and $P$ respectively.

In a steady-state these fluxes are equal, so that,

hence,

$$
I^{*}+C \times S_{P}=(J+C) \times S_{X}
$$

or, letting $R=I^{*} / S_{X}$,

$$
I^{*} / S_{X}=J+C \times\left(1-S_{P} / S_{X}\right)
$$$$
R=J+C \times\left(1-S_{P} / S_{X}\right) .
$$

Under steady-state conditions the isotopic fluxes which produce labelled $X$ equal those which remove the label, so that there is no net labelling of $X$. This constraint enables a set of 'balanced' isotopic-flux equations to be written and then solved to yield the mass fluxes (i.e. reaction and pathway rates) in terms of the specific activities of the labelled intermediates (or carbon atoms) and the rate of supply of labelled precursor.

Fig. 1 (which includes eqn (1)) shows how this approach can be applied to a system in which a product, $P$, can be either metabolized further or recycled to substrate $X$. The input of isotope, $I^{*}$, may represent either the rate of isotope infusion into a precursor pool such as blood, or the net uptake of labelled blood-borne substrate by an organ. In the latter case, from the definition of specific activity:

$$
\begin{aligned}
& \text { amount of tracer per vol. arterial blood }=c_{\mathrm{a}} \times S_{\mathrm{a}}, \\
& \text { amount of tracer per vol. venous blood }=c_{\mathrm{v}} \times S_{\mathrm{v}},
\end{aligned}
$$

where $c_{\mathrm{a}}$ and $c_{\mathrm{v}}$ are the concentrations of substrate in arterial and venous blood and $S_{\mathrm{a}}$ and $S_{\mathrm{v}}$ their respective specific activities.

Therefore,

$$
\text { rate of tracer uptake }\left(I^{*}\right)=\text { blood flow } \times\left(c_{\mathrm{a}} \times S_{\mathrm{a}}-c_{\mathrm{v}} \times S_{\mathrm{v}}\right) .
$$

In experiments to determine whole-body fluxes the function $R$ (i.e. the rate of infusion of tracer divided by its blood specific activity; see Fig. 1) is often used as a measure of the flux of $X$, and is often referred to as an 'entry rate' or an 'irreversible loss rate'. However, eqn (2) (Fig. 1) shows that, if there is recycling of $X$ (at a rate $C$ ), the value of $R$ does not equal any of the fluxes in the system unless the specific activity of the product $\left(S_{P}\right)$ is 
either zero or is equal to the specific activity of the substrate $\left(S_{X}\right)$. In the former case $\left(S_{P}\right.$ $=0$ ), $X$ behaves as an 'irreversible tracer' and $R$ measures the actual 'gross' flux, $J+C$ : in the latter case $\left(S_{P}=S_{X}\right) R$ measures the actual net flux (or irreversible loss rate), $J$. Therefore, if there is recycling of label, the value of $S_{P}$ relative to $S_{X}$ must be determined in order to evaluate the quantitative significance of measured values of $R$.

For trans-organ studies (using eqn (2a)):

$$
R=\text { blood flow } \times\left(c_{\mathrm{a}} \times S_{\mathrm{a}}-c_{\mathrm{v}} \times S_{\mathrm{v}}\right) / S_{X},
$$

which is often simplified by assuming that the specific activity of the substrate in venous blood, $S_{\mathrm{v}}$, is the same as that in the tissue, $S_{X}$ (although, since the venous flow may contain some material derived directly from the arterial flow, this simplifying assumption is not necessarily correct). With this assumption for $R$, eqn (2) (Fig. 1) becomes:

$$
\text { blood flow } \times\left(c_{\mathrm{a}} \times S_{\mathrm{a}}-c_{\mathrm{v}} \times S_{\mathrm{v}}\right) / S_{\mathrm{v}}=J+C \times\left(1-S_{\mathrm{P}} / S_{\mathrm{v}}\right) .
$$
into:

Since the net mass flux, $J,=$ blood flow $\times\left(c_{\mathrm{a}}-c_{\mathrm{v}}\right)$, this equation can be rearranged

$$
C=\text { blood flow } \times c_{\mathrm{a}} \times\left(S_{\mathrm{a}}-S_{\mathrm{v}}\right) /\left(S_{\mathrm{v}}-S_{P}\right) .
$$

This equation shows that the rate of cycling, $C$, can be measured by infusing singly-labelled (e.g. ${ }^{14} \mathrm{C}$ ) $X$ or a suitable precursor of $X$; provided that (1) $S_{P}$ can be measured or calculated indirectly and (2) $S_{P}$ is less than $S_{\mathrm{v}}$, i.e. the tracer in the product $P$ is 'diluted' relative to that in $X$. (In other words, the diluting flux, $D$, in Fig. 1 must not be zero.) As discussed later, measuring $S_{P}$ or eliminating it from equations analogous to eqn (3) can sometimes be quite difficult, and may preclude an accurate determination of the rate of cycling in vivo.

\section{Measuring of $\mathrm{X} \rightleftharpoons \mathrm{P}$ interconversions when both $\mathrm{X}$ and $\mathrm{P}$ can be sampled}

If the cycle product, $P$ (Fig. 1), is experimentally accessible $S_{P}$ can be measured directly and the value of $C$ then calculated from equations analogous to eqn (3). Furthermore, an additional isotopic balance equation for the labelling of $P$ :

$$
(J+C) \times S_{X}=S_{P} \times(C+J+D),
$$

enables the diluting flux, $D$, to be calculated. Moreover, if a different label is introduced directly into $P$ (so that $I^{*}$ for this label enters at $P$ rather than $X$ ), two more distinct isotopic-balance equations for the labelling of $X$ and $P$ may be written, giving even more information about the fluxes in the system.

This approach has been used by Tessari et al. (1985) to measure the rate of exchange (transamination) between leucine and its oxo(keto)-acid, 4-methyl-2-oxo-pentanoate (MOP). In these investigations the whole-body pools of leucine and MOP were labelled simultaneously with different isotopes (e.g. $\left[{ }^{3} \mathrm{H}\right]$ leucine and $\left[1-{ }^{14} \mathrm{C}\right] \mathrm{MOP}$ ) and the four isotopic balance equations solved simultaneously to give the rate of exchange, $C$, and several related fluxes.

\section{Measuring rates of cycling by labelling a large pool of substrate}

If the amount of $X$ (Fig. 1) is relatively large and label can be introduced directly into the product $P$ then, for short incubation periods, the rate of cycling $(C)$ can be measured as the rate of labelling of substrate $X$ (which acts as a short-term isotope 'sink'). Although this is a pre-steady rather than a steady-state technique it has been used to measure cycling between pyruvate, oxaloacetate and phosphoenolpyruvate in rat liver (Rognstad, 1975; Katz \& Rognstad, 1976). More recently the same principle has been 
used to measure the re-esterification component of the cycle between triacylglycerol and fatty acids in white adipose tissue (Brooks et al. 1982, 1983).

\section{Acetate-acetyl-CoA cycle in sheep muscle}

When $P$ (Fig. 1) is a tissue intermediate which does not enter or have access to the blood, a direct determination of $S_{P}$ is usually not possible. However, in some cases, $S_{P}$ may be estimated indirectly, as with the substrate cycle between acetate and acetyl-CoA in sheep muscle (Crabtree et al. 1987). This cycle (Fig. 2) occurs in the mitochondria of several mammalian tissues and also in the cytoplasm of rat liver where it is especially active (Rabkin \& Blum, 1985; Jessop et al. 1986). Its role in vivo is still unclear, but it may provide an acetate-controlled ATPase (EC 3.6.1.8) which would enable excess acetate to be oxidized rather than stored as fat. Its activity in sheep muscle in vivo was first estimated by Pethick $e t$ al. (1981) and has been studied in more detail since (Crabtree $e t$ al. 1987). Isotope input into the muscle was by arterio-venous uptake after infusing a singly-labelled substrate $\left(\left[1-{ }^{14} \mathrm{C}\right]\right.$ acetate $)$ into a jugular vein. Dilution of the cycle product, acetyl-CoA (equivalent to $P$ in Fig. 1), was provided by the oxidation of unlabelled fuels, e.g. glucose, fatty acids and ketone bodies. Since $S_{P}$ refers, in this example, to the specific activity of mitochondrial acetyl-CoA $\left(S_{\text {acetyl-CoA }}\right)$, it would be difficult if not impossible to measure it directly in vivo. However, in muscle the value of $S_{\text {acetyl-CoA }}$ can be estimated by assuming that acetate labels a single pool of mitochondrial acetyl-CoA which participates in only two reactions: condensation with oxaloacetate in the tricarboxylic acid cycle $(K)$ and recycling to acetate $(C)$. (It must be stressed that in other tissues, especially liver and adipose tissue, these assumptions are not valid.)

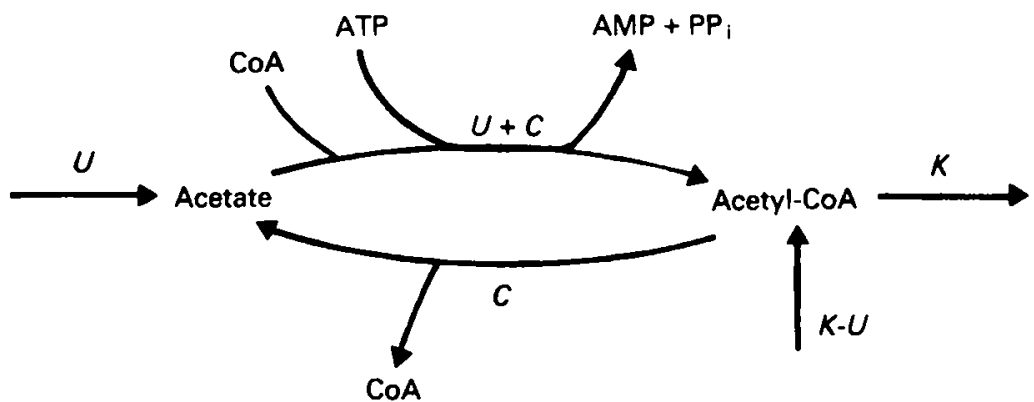

Fig. 2. Acetate-acetyl-CoA cycle in muscle. The symbols are as used by Crabtree et al. (1987). $C$, rate of acetyl-CoA hydrolysis; $U$, net flux of acetate to acetyl-CoA ( $J$ in Fig. 1$) ; K$, tricarboxylic acid cycie; $K-U$, flux of acetyl-CoA from unlabelled fuels ( $D$ in Fig. 1); acetate and acctyl-CoA are $X$ and $P$ respectively in Fig. 1 . The specific radioactivity of acetyl-CoA ( $S_{P}$ in Fig. 1 legend) is obtained from an isotopic balance equation for the labelling of acetyl-CoA,

$$
(U+C) \times S_{\text {acetate }}=(K+C) \times S_{\text {acetyl-CoA }}
$$

which, when combined with eqn (3) (see p. 355), gives the equation

$$
C=\frac{\left(\text { blood flow } \times K \times c_{\mathrm{v}} \times\left(S_{\mathrm{u}} / S_{\mathrm{v}}-1\right)\right.}{K+\text { blood flow } \times\left(c_{\mathrm{v}}-c_{\mathrm{u}} \times S_{\mathrm{a}} / S_{\mathrm{v}}\right)}
$$

where $c_{v}$ and $c_{v}$ are arterial and venous concentrations of acetate respectively, and $S_{\mathrm{u}}$ and $S_{\mathrm{v}}$ are the corresponding specific activities. $K$ is calculated as $(U+O) / 3$, where $O$ is the rate of oxygen uptake (see Crabtree et al. (1987) for further details). 


\section{Table 1. Acetate cycle and associated fluxes in sheep hind-limb muscle}

(The values refer to sheep no. 6584 (Crabtree et al. 1987) which was infused intravenously with $2 \mathrm{~mol} / \mathrm{d}$ of either sodium chloride or sodium acetate (to elevate blood acetate concentration))

\begin{tabular}{|c|c|c|c|c|c|c|c|c|c|c|}
\hline \multirow[b]{2}{*}{ Infusion } & \multirow[b]{2}{*}{$\begin{array}{l}\text { Blood flow } \\
\text { (1/kg per } \mathrm{min})\end{array}$} & \multirow{2}{*}{\multicolumn{2}{|c|}{$\underset{(\mathrm{mmol} / \mathrm{l} \text { blood })}{c_{\mathrm{a}}} \stackrel{c_{\mathrm{v}}}{ }$}} & \multicolumn{6}{|c|}{ Fluxes $(\mathrm{mmol} / \mathrm{kg}$ per $\mathrm{min})$} & \multirow[b]{2}{*}{$\begin{array}{c}S_{\text {acetyl-CoA }} \\
S_{\text {acetate }}\end{array}$} \\
\hline & & & & $S_{\mathrm{a}} / S_{\mathrm{v}}$ & $U$ & $O$ & $K$ & $C$ & $C_{\mathrm{o}}$ & \\
\hline & $\begin{array}{l}0.11 \\
0.10\end{array}$ & $0 \cdot 6$ & $\begin{array}{l}0.46 \\
0.57\end{array}$ & $\begin{array}{l}1 \cdot 12 \\
1 \cdot 12\end{array}$ & 0.018 & 0.32 & 0.11 & 0.016 & 0.006 & 0.28 \\
\hline
\end{tabular}

$c_{\mathrm{a}}$ and $c_{\mathrm{v}}$ are the arterial and venous concentrations of acetate respectively; $S_{\mathrm{a}}$ and $S_{\mathrm{v}}$ are the corresponding specific activities; $S_{\text {acetyl-CoA }}$ is the (estimated) specific activity of acetyl-CoA; $U$ is the net uptake of acetate; $O$ is the net uptake of oxygen; $K$ is the (estimated) rate of the tricarboxylic acid cycle.

The rate of cycling, $C$, was calculated from eqn (4) (Fig. 2); and $C_{n}$ is the rate of cycling calculated by assuming no ${ }^{14} \mathrm{C}$-labelling of acetyl-CoA (i.e. by setting $S_{P}$ to zero in eqn (3); see p. 355 ).

The resulting derivations are shown in Fig. 2 (Fig. 2 also includes eqn (4)). The calculated acetate-acetyl-CoA cycling rate, $C$, is low and apparently not much influenced by increasing the blood acetate concentration (Table 1); suggesting that a direct effect of acetate on this particular cycle in muscle is of minimal importance in disposing of excess acetate. (In contrast, the same cycle in liver may be much more important (Jessop et al. 1986).) It should also be noted that, if the labelling of acetyl-CoA is not taken into account, the rate of cycling may be underestimated by as much as three- to fourfold (Table 1).

Measuring cycling or reversible-exchange rates using a substrate labelled with two different isotopes

As will be appreciated from the previous comments, a major problem with using a single isotope is the need to measure or estimate the specific activity of the cycle product $\left(S_{P}\right)$. Moreover, if the tracer in the product $P$ is not diluted relative to that in $X$ (i.e. if $S_{P}$ $=S_{X}$ ) then the method cannot be used to estimate cycling at all.

These problems may be surmounted by eliminating ' $S_{P}$ ' from the equations by labelling $X$ with isotopes which are metabolized differently during the appropriate reactions. For example, if one isotope is completely diluted (or exchanged, or both) at $P$ (so that $S_{P}=0$ ) while the other is not diluted at all (so that $S_{P}=S_{X}$ ), the two respective ' $R$ values' $\left(R^{(1)}\right.$ and $R^{(2)}$ ) will equal $J+C$ and $J$ respectively (Fig. 1): their difference will thus equal $C$, the cycling rate.

This simple method has been used to measure the rate of Cori (lactate) and alanine cycling between blood glucose and lactate-pyruvate-alanine (Fig. 3; see Katz \& Rognstad, 1976; Schulman et al. 1985). In this case $\left[{ }^{14} \mathrm{C}\right.$ glucose provides a label which is not exchanged in the metabolic transformations whereas $\left[6-{ }^{3} \mathrm{H}\right]$ glucose provides one that is almost completely lost by exchange at lactate-pyruvate. Thus,

$$
\text { Cori }+ \text { alanine cycling }=R\left(\left[{ }^{3} \mathrm{H}\right] \text { glucose }\right)-R\left(\left[{ }^{14} \mathrm{C}\right] \text { glucose }\right) \text {. }
$$

Use of mass-cluster analysis. An interesting extension of the previously described approach is based on the ability to separate and measure stable isotopes of glucose according to their mass (Tserng \& Kalhan, 1983b). The administration of $\left[\mathrm{U}-{ }^{13} \mathrm{C}\right]$ glucose provides some molecules which are labelled in all six carbon atoms (thus giving rise to an ' $m+6$ ' mass species, where $m$ refers to [U-12C]glucose); and, during glycolysis, these molecules are cleaved into two ' $m+3$ ' triose phosphates. If the number of tracer 


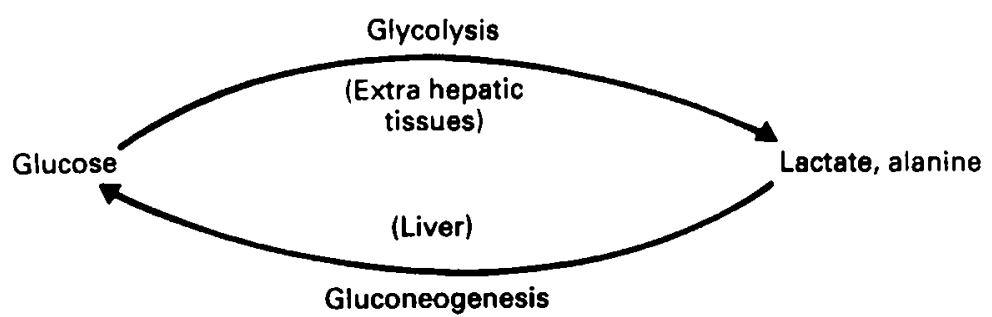

Fig. 3. Cori (lactate) and alanine cycle. This cycle serves to recycle carbohydrate, especially during periods of starvation (see Newsholme \& Leech, 1983), and has recently been shown to be involved in the disposal of dietary glucose after a period of fasting (the so-called 'glucose paradox': see McGarry et al. 1987).

molecules is small compared with the total body pool it is highly unlikely that, during the reverse reaction of the Cori cycle (i.e. gluconeogenesis), two ' $m+3$ ' molecules will meet and recombine to give an ' $m+6$ ' hexose. The ' $m+6$ ' glucose thus behaves as an irreversible tracer (analogous to [6- $\left.{ }^{3} \mathrm{H}\right]$ glucose) and, by measuring the values of ' $R$ ' for both this species and the $\mathrm{C}-1$ atom of glucose (which provides a label analogous to $\left[{ }^{14} \mathrm{C}\right]$ glucose), the rate of cycling can be obtained by difference (Tserng \& Kalhan, $1983 b)$.

A similar example is the use of $\left[1-{ }^{13} \mathrm{C},{ }^{15} \mathrm{~N}\right]$ leucine to measure (amongst other things) the transamination exchange between leucine and MOP mentioned earlier. Since the probability of doubly-labelled leucine being reformed is very low, this species serves as an irreversible tracer for the gross flux $(J+C)$ of leucine to MOP. Application of this method to the human forearm (which is predominantly muscle) has revealed how sensitive protein metabolism, leucine transamination and MOP decarboxylation are to nutritional state (Cheng et al. 1985, 1987; see Table 2).

Table 2. Leucine metabolism across the human forearm as influenced by nutritional state

(Values from arterio-venous measurements described by Cheng et al. $(1985,1987)$. Tracer was $[1-13 \mathrm{C}$, $\left.{ }^{15} \mathrm{~N}\right]$ leucine. In principle the transamination exchange between lcucine and MOP was calculated from the difference between net flux ( $J$, Fig. 1$)$, assessed by movement of ${ }^{13} \mathrm{C}$ label, and total flux $(J+C$, Fig. 1$)$, assessed by the movement of ${ }^{15} \mathrm{~N}$ isotope. Oxidation was based on the production of ${ }^{13} \mathrm{CO}_{2}$, while protein synthesis and degradation were calculated from net isotope and mass movement)

\begin{tabular}{lrr} 
& Rates (nmol// forearm per min) \\
\cline { 2 - 3 } & Fasted & Fed \\
Protein metabolism & 700 & 1270 \\
Synthesis & 980 & 870 \\
Degradation & -290 & 390 \\
Balance & & \\
Leucine interconversion & 2090 & 3880 \\
$\quad$ Leucine to MOP & 1990 & 3300 \\
$\quad$ MOP to leucine & & \\
Leucine oxidation & 50 & 430 \\
MOP to carbon dioxide & 50
\end{tabular}

MOP, 4-methyl-2-oxo-pentanoate. 


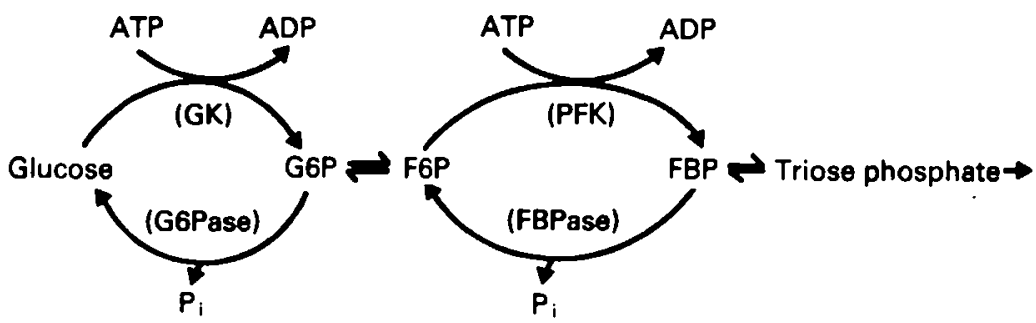

Fig. 4. Substrate cycles of glycolysis-gluconeogenesis. Both cycles operate in the liver of many mammalian species whereas, in muscle, only the fructose-6-phosphate (F6P)-fructose-1,6,-bisphosphate (FBP) cycle operates. GK, glucokinase (EC 2.7.1.2); G6Pase, glucose-6-phosphatase (EC 3.1.3.9); PFK, 6-phosphofructokinase-1 (EC 2.7.1.11); FBPase, fructose-1,6,-bisphosphatase (EC 3.1.3.11).

This type of 'mass cluster' analysis has no counterpart in radioisotopic analysis (in which isotopes can only be distinguished by their energy spectra; which would be identical for the ' $m+3$ ' and ' $m+6$ ' species of $\left[{ }^{14} \mathrm{C}\right]$ glucose). It can therefore provide kinetic information that is unobtainable by using radioactive isotopes alone; and may be of great value in future investigations of complex systems, for example those which occur in association with the tricarboxylic acid cycle.

Substrate cycles associated with glucose metabolism. ${ }^{3} \mathrm{H}$-labelled glucose has also been used to measure the rates of two important substrate cycles associated with glycolysis: between glucose and glucose-6-phosphate (G6P) and between fructose-6-phosphate (F6P) and fructose-1,6-bisphosphate (FBP) (Fig. 4). These cycles may be important in providing sensitivity for control and, since they are accompanied by ATP hydrolysis, they may also serve to control heat production and the disposal of 'excess' nutrients (see Newsholme \& Crabtree, 1976; Newsholme et al. 1984). An isotopic technique for measuring their rates in isolated cells or tissue preparations (Bloxham et al. 1973; Clark et al. 1973a,b; Hue \& Hers, 1974) has recently been extended to investigations in vivo (e.g. Karlander et al. 1986). It relies on the exchange of ${ }^{3} \mathrm{H}$ from $\mathrm{C}-2$ of glucose during the interconversion of G6P and F6P, and exchange from $\mathrm{C}-3$ or $\mathrm{C}-5$ during the interconversions of triose phosphates. These exchanges lead to a loss of ${ }^{3} \mathrm{H}$ from the respective cycle products, G6P and F6P. Therefore, by analogy with the Cori-alanine cycles, $\left[2-{ }^{3} \mathrm{H}\right]$ glucose and $\left[3-{ }^{3} \mathrm{H}\right]$ glucose have been used as 'irreversible' tracers to measure the 'gross flux' $(J+C)$ across the glucose-G6P and F6P-FBP cycles respectively, in liver in vivo. The value of $C$ was then obtained by subtracting the $R$ function for $\left[6-{ }^{3} \mathrm{H}\right]$ glucose which, as discussed earlier, measures the net glycolytic flux, $J$ (Karlander et al. 1986). A similar study, using stable isotopes (2-D, 3-D- and 6,6, $\mathbf{D}_{2}$-glucose), has shown that thyroid hormones may affect the rates of both cycles (Schulman et al. 1985).

Unfortunately, these studies do not provide accurate measurements of substrate cycling in vivo for at least three reasons. First, $\left[6^{-}{ }^{3} \mathrm{H}\right]$ glucose measures the rate of glycolysis in all tissues, whereas the glucose-G6P cycle operates principally if not exclusively in the liver. Second, only the liver F6P-FBP cycle will affect the ' $R$ ' value for blood $\left[3-{ }^{3} \mathrm{H}\right]$ glucose because most extrahepatic tissues lack G6Pase (EC 3.1.3.9) activity and hence cannot transmit a loss of ${ }^{3} \mathrm{H}$ from their hexose phosphate pool back to blood glucose; thus muscle F6P-FBP cycling will not be detected. Consequently, the rates of both these cycles will be underestimated by subtracting the $R$ function for blood $\left[6-{ }^{3} \mathrm{H}\right]$ glucose (i.e. the total glycolytic flux of many tissues) from that for blood $\left[2-{ }^{3} \mathrm{H}\right]-$ or $\left[3-{ }^{3} \mathrm{H}\right]$ glucose (which refers only to the fluxes in liver). Third, as the investigators 
Table 3. Retention of ${ }^{3} \mathrm{H}$ in fructose-1,6-bisphosphate $(F B P)$ and errors in fructose-6phosphate (F6P):FBP cycling caused by neglecting it

$\begin{array}{lc} & \begin{array}{c}\text { Percentage of the } \\ \text { ratio in administered } \\ \text { glucose }\end{array} \\ { }^{3} \mathrm{H}:{ }^{14} \mathrm{C} \text { ratio of hexose phosphate }\left(S_{1}\right) & 98 \cdot 5 \\ { }^{3} \mathrm{H}:{ }^{14} \mathrm{C} \text { ratio of FBP }\left(S_{2}\right) & 70 \cdot 4 \\ \text { Net glycolytic flux }(G) & \mu \mathrm{mol} / \mathrm{h} \mathrm{per} \mathrm{g} \\ \text { F6P:FBP cycling }(C) & 3 \cdot 8 \\ \text { Cycling assuming all }{ }^{3} \mathrm{H} \text { lost from FBP } & 0.22 \\ \alpha\left(S_{2} / S_{1}\right) & 0.06 \\ \end{array}$

Values from Challis et al. (1984a) in which isolated rat epitrochlearis muscles were incubated with $\left[5-{ }^{3} \mathrm{H}\right]$ g]ucose and $\left[6-{ }^{14} \mathrm{C}\right.$ glucose.) $C=G\left(100-S_{1}\right) /\left(S_{1}-S_{2}\right)$ and cycling assuming all ${ }^{3} \mathrm{H}$ is lost from FBP (i.e. with $S_{2}$ zero) $=G\left(100-S_{1}\right) / S_{1}$, where $G$ is the rate of lactate production and $S_{1}, S_{2}$ are expressed as percentages of the ${ }^{3} \mathrm{H}:{ }^{14} \mathrm{C}$ ratio of the administered glucose. These equations, derived specifically for this cycle by Newsholme \& Crabtree (1976), may be deduced from eqn (5) (see below) by noting that $J$ is equivalent to $G$ and $R$ is the rate of labelling of hexose phosphate from glucose divided by the specific radioactivity (SRA) of hexose phosphate. Thus:

$$
\begin{aligned}
R^{(1)}\left(\text { i.e. } R^{14} \mathrm{C}\right) & =G \times\left({ }^{14} \mathrm{C}-\mathrm{SRA} \text { of glucose: }{ }^{14} \mathrm{C}-\mathrm{SRA} \text { of hexose phosphate }\right) \\
& =G\left(\text { assuming no dilution of }{ }^{14} \mathrm{C} \text { in the system }\right) \\
R^{(2)}\left(\text { i.e. } R^{3} \mathrm{H}\right) & =G \times\left({ }^{3} \mathrm{H}-\mathrm{SRA} \text { of glucose: }{ }^{3} \mathrm{H}-\mathrm{SRA} \text { of hexose phosphate }\right) \\
& =G \times 100 / S_{1} .
\end{aligned}
$$

themselves recognized, the loss of ${ }^{3} \mathrm{H}$ from G6P and FBP is almost certainly incomplete, i.e. $S_{P}>0$ (see Katz \& Rognstad, 1976), and neglecting this leads to a further underestimation of the rate of cycling (Newsholme \& Crabtree, 1976). For example, in isolated muscle, as much as $70 \%$ of the ${ }^{3} \mathrm{H}$ in FBP can be retained and this may introduce errors of nearly fourfold in the rate of cycling (i.e. $0.22 v .0 .06 \mu \mathrm{mol} / \mathrm{h}$ per g; Table 3). A consequence of this particular underestimation is that the contributions to thermogenesis in vivo of F6P-FBP cycling in both the flight muscles of bumble bees (Clark et al. 1973a) and in malignant hyperthermic pig muscle (Clark et al. 1973b) may be much greater than reported. For example, the contribution of the F6P-FBP cycle to the increased heat production in hyperthermic pigs, calculated as $10-20 \%$ by Katz \& Rognstad (1976), could be as much as $40-80 \%$ if the retention of ${ }^{3} \mathrm{H}$ in FBP is similar to that in rat muscle (Table 3).

Use of isotope ratios in the product, $\mathrm{P}$, to measure cycling. Since isotope may be only partially exchanged, we must consider the general situation where $S_{P}>0$ and $S_{P}=S_{X}$. For each of two differently-metabolized labels (1 and 2) the solutions of eqn (2) (Fig. 1) are:

$$
\begin{aligned}
& R^{(1)}=J+C \times\left(1-S_{P 1} / S_{X 1}\right), \\
& R^{(2)}=J+C \times\left(1-S_{P_{2}} / S_{\mathrm{X} 2}\right) .
\end{aligned}
$$

By setting $\alpha=\left[S_{P 2} / S_{P_{1}}\right] /\left[S_{X 2} / S_{X 1}\right]$ so that $\alpha=$ [ratio of isotope 2:isotope 1 in a sample of $P] /[$ ratio of isotope 2:isotope 1 in a sample of $X]$,

$$
R^{(2)}=J+C \times\left(1-\alpha S_{P 1} / S_{\mathrm{X} 1}\right) .
$$

Combining this with the equation for $R^{(1)}$ gives

$$
J+C=\left[\alpha R^{(1)}-R^{(2)}\right] /[\alpha-1]
$$


An advantage of this approach is that only the ratio of the two isotopes in the product needs to be determined and not their individual specific activities. Thus, when samples are limited (e.g. with tissue biopsies), carrier metabolites can be added to facilitate purification (although, with stable isotopes, the small amounts of isotope present in the carrier must be allowed for). Another advantage is that any intracellular dilutions of $X$ or $P$ will affect both isotopes equally, so that the isotope ratio, and hence the value of $\alpha$, is unchanged (although such dilutions of $X$ may give rise to erroneous values for ' $R$ '; see below).

Eqn (5) is quite general and may be applied to a whole-body cycle (where $R$ is the rate of infusion of isotope divided by $S_{X}$ ), a cycle in a defined organ or tissue region (where $R$ is blood flow multiplied by $\left.\left(c_{\mathrm{a}} S_{\mathrm{a}}-c_{\mathrm{v}} S_{\mathrm{v}}\right) / S_{\mathrm{v}}\right)$, or a cycle in an isolated tissue. For example, by using glucose labelled with ${ }^{14} \mathrm{C}$ at $\mathrm{C}-6$, and ${ }^{3} \mathrm{H}$ on $\mathrm{C}-5$, this equation (although not explicitly in the form given here) has been used to calculate the rate of F6P-FBP cycling in isolated rat muscles (see Table 3 ).

Since eqn (5) gives only the 'gross uptake', $(J+C)$, to obtain $C$ it is usually necessary to measure the net flux, $J$, by an alternative procedure (for example, in Table 3 the net flux, $G$, was measured as the rate of lactate production). For trans-tissue measurements $J$ is the net mass uptake; obtained as the product of blood flow and arterio-venous concentration difference. For whole-body kinetics $J$ must be measured by using an alternative label; for example, the use of $\left[6-{ }^{3} \mathrm{H}\right]$ glucose to measure the net glycolytic flux, i.e. ' $\boldsymbol{J}$, for substrate cycling in vivo between glucose and G6P, and between F6P and FBP.

\section{Some problems which may be encountered when measuring cycling with tracers}

At least three important points must be considered when using tracers to measure cycling rates. First, there must be no loss of label from $X$ caused by factors other than the cycle. For example, in liver an active transaldolase (EC 2.2.1.2) catalyses an exchange of C-4-C-6 of G6P with triose phosphate, with a consequent loss of ${ }^{3} \mathrm{H}$ from $\mathrm{C}-5$ of hexose phosphate. Therefore, $\left[5-{ }^{3} \mathrm{H}\right]$ glucose cannot be used to measure F6P-FBP cycling in liver. Although $\left[3-{ }^{3} \mathrm{H}\right]$ glucose is not affected by this particular problem, false values for cycling may still be obtained with this labelled species if the rate of the pentose phosphate cycle is high (see Katz \& Rognstad, 1976). However, in muscle there is little, if any, transaldolase activity (Challis, 1983) and the rate of the pentose phosphate cycle is extremely low; so that either of these tritiated glucoses may be confidently used to measure the F6P-FBP cycle in that tissue. Indeed, the use of $\left[6-{ }^{14} \mathrm{C}\right]:\left[5-{ }^{3} \mathrm{H}\right]$ glucose to measure this cycle in muscle has been validated by comparison with a single-isotope technique in which $\left[6-{ }^{14} \mathrm{C}\right]$ glucose was added to a muscle preparation and the rate of F6P-FBP cycling calculated from the $\left[1-{ }^{14} \mathrm{C}\right]:\left[6-{ }^{14} \mathrm{C}\right]$ ratios in FBP and hexose phosphates (Challis et al. 1984b).

Second, there must be a rapid and reversible exchange of the intracellular and extracellular pools of the substrate, $X$, i.e. these two pools must be in near-equilibrium. If this is not so, any dilution of labelled $X$ (or decrease in its specific activity due to cycling) in the cell will not be reflected in the specific activity of $X$ in the sampling pool (i.e. blood, cell culture or incubation medium). The specific activity in the sampling pool will then be greater than that in the cell and hence the value of ' $R$ ' will be underestimated (see eqns (1) and (2) in Fig. 1). This problem may be difficult to resolve (or even detect) and is exemplified by the difficulties of deciding which specific activity best represents the precursor pool for protein synthesis (see Waterlow et al. 1978). Moreover, the assumption that $S_{X}=S_{\mathrm{v}}$, made when deriving eqn (3), only applies when there is a rapid 
exchange between the extracellular and intracellular pools of $X$. Indeed, in the extreme situation where the uptake of $X$ is totally irreversible, changes of $S_{X}$ in the cell will not be communicated to $X$ in the sampling pool at all, so that any intracellular cycling between $X$ and $P$ (Fig. 1) would not even be detected by measuring $S_{X}$ in the sampling (extracellular) pool. (As mentioned earlier, the irreversibility of glucose uptake and phosphorylation in muscle prevents substrate cycling between F6P and FBP in this tissue from being detected using blood $\left[3-{ }^{3} \mathrm{H}\right]$ glucose in vivo.)

Third, if $P$ is an intermediate which occurs in more than one intracellular compartment, or if significant channelling of $P$ occurs (see Srivastava \& Bernhard, 1986), the overall tissue isotope ratio $(\alpha)$ may not reflect that at the intracellular site of the reaction of interest. It may often be difficult to overcome this particular problem, but a possible specific solution is given in the next section.

Use of $\left[{ }^{18} \mathrm{O}\right]:{ }^{13} \mathrm{Clacetate}$ to measure the acetate-acetyl $\mathrm{CoA}$ cycle. In the reaction catalysed by acetyl-CoA synthetase (EC 6.2.1.1)

$$
\mathrm{CH}_{3} \mathrm{COOH}+\mathrm{CoA} . \mathrm{SH} \rightarrow \mathrm{CH}_{3} \text { CO.S.COA }+\mathrm{H}_{2} \mathrm{O} \text {, }
$$

one oxygen atom of the carboxyl group (i.e. half the total $\mathrm{O}$ ) is lost to water. This loss is essentially irreversible, because the probability of a carboxyl-derived ${ }^{18} \mathrm{O}$ atom being returned from water to acetate during the subsequent hydrolysis of acetyl-CoA (see Fig. 2 ) is extremely low. Consequently, it is reasonable to assume that, for acetate labelled with ${ }^{13} \mathrm{C}$ and ${ }^{18} \mathrm{O}$, the value of $\alpha$ (i.e. ${ }^{18} \mathrm{O}:{ }^{13} \mathrm{C}$ ratio of acetyl-CoA relative to acetate) is $0 \cdot 5$. Eqn (5) then reduces to,

$$
J+C=2 R^{(18)}-R^{(13)} .
$$

Since $\alpha$ does not need to be measured, complications arising from the nature of the acetyl-CoA compartment do not arise. However, it would be essential to ensure that exchange of ${ }^{18} \mathrm{O}$ with water- $\mathrm{O}$ does not occur during extraction or analysis of the acetate; or even during the synthetase reaction.

A similar approach using $\left[{ }^{14} \mathrm{C}\right]$ - and $\left[2,3\right.$-side-chain $\left.{ }^{3} \mathrm{H}\right]$ tyrosine has been used to measure the extent of transamination-reamination that occurs with tyrosine in rabbit tissues (Nicholas et al. 1977). During transamination the $\mathrm{H}$ atom at C-2 (i.e. half the ${ }^{3} \mathrm{H}$ label) is lost, so that exactly the same analysis can be applied as for $\left[{ }^{18} \mathrm{O}:{ }^{13} \mathrm{C}\right]$ acetate.

\section{Conclusions}

Although we have discussed relatively simple examples, the general approach of writing and solving a set of isotopic-'balance' equations for each intermediate can be readily extended to more complicated systems (see Nolan et al. 1976; Katz \& Grunnet, 1979; Blum \& Stein, 1982). Experiments involving isotope infusions or incubations can, therefore, provide considerable information about complex metabolic fluxes in vivo, especially if several different isotopes are used (e.g. Egan et al. 1983; Rabkin \& Blum, 1985). Even more information can be obtained by measuring the isotopic activities of the individual atoms of the metabolic intermediates (see Wiltrout \& Satter, 1972; Williams et al. 1987), but, until recently, this always required chemical or enzymic degradations, or both, which can be inaccurate and time-consuming. However, newer techniques (especially nuclear magnetic resonance) now allow the distribution of stable isotopes in several intermediates to be measured without degrading the molecules, thereby making valuable additional kinetic information more readily accessible (e.g. Cohen et al. 1979; Cohen, 1983, 1987; Pahl-Wostl \& Seelig, 1986; Malloy et al. 1987). These newer approaches offer exciting possibilities for future investigations. However, it must always be remembered that they rely on the same basic principles as (and share many potential 
pitfalls with) conventional tracer techniques which, in our opinion, will continue to play a major role in metabolic research for the foreseeable future.

The authors would like to thank Dr Chris Hodgson of the Moredun Institute, Edinburgh, and Dr John MacRae for helpful and constructive criticisms of the manuscript.

\section{REFERENCES}

Bloxham, D. P., Clark, M. G., Holland, P. C. \& Lardy, H. A. (1973). Biochemical Journal 134, 584-587.

Blum, J. \& Stein, R. B. (1982). In Biological Regulation and Development, pp. 99-125 [R. F. Goldberg and K. R. Yamomoto, editors]. New York: Plenum Press.

Brooks, B. J., Arch, J. R. S. \& Newsholme, E. A. (1982). FEBS Letters 146, 327-330.

Brooks, B. J., Arch, J. R. S. \& Newsholme, E. A. (1983). Bioscience Reports 3, 263-267.

Challis, R. A. J. (1983). Studies on substrate cycling in muscle. DPhil Thesis, Oxford University.

Challis, R. A. J., Arch, J. R. S., Crabtree, B. \& Newsholme, E. A. (1984b). Biochemical Journal 223, 849-853.

Challis, R. A. J., Arch, J. R. S. \& Newsholme, E. A. (1984a). Biochemical Journal 221, 153-161.

Cheng, K. N., Dworzak, F., Ford, G. C., Rennie, M. J. \& Halliday, D. (1985). European Journal of Clinical Investigation 15, 349-354.

Cheng, K. N., Pacy, P. J., Dworzak, F., Ford, G. C. \& Halliday, D. (1987). Clinical Science 73, 241-246.

Clark, M. G., Bloxham, D. P., Holland, P. C. \& Lardy, H. A. (1973a). Biochemical Journal 134, 589-597.

Clark, M. G., Williams, C. H., Pfeifer, W. F., Bloxham, D. P., Holland, P. C., Taylor, C. A. \& Lardy, H. A. (1973b). Nature 245, 99-101.

Cohen, S. M. (1983). Journal of Biological Chemistry 258, 14294-14303.

Cohen, S. M. (1987). Biochemistry 26, 563-572, 573-580, 581-589.

Cohen, S. M., Ogawa, S. \& Schulman, R. G. (1979). Proceedings of the National Academy of Sciences, USA 76, 1603-1607.

Crabtree, B., Marr, S. A., Anderson, S. E. \& MacRae, J. C. (1987). Biochemical Journal 243, 821-827.

Egan, A. R., MacRae, J. C. \& Lamb, C. S. (1983). British Journal of Nutrition 49, 373-383.

Hetenyi, G. (1981). In Carbohydrate Metabolism, pp. 201-219 [C. Cobelli and R. N. Bergman, editors]. New York: Wiley \& Sons.

Hue, L. \& Hers, H.-G. (1974). Biochemical and Biophysical Research Communications 58, 532-539.

Jessop, N. S., Smith, G. H. \& Crabtree, B. (1986). Biochemical Society Transactions 14, 146-147.

Karlander, S., Roovete, A., Vranic, M. \& Efendic, S. (1986). American Journal of Physiology 251, E530-E536.

Katz, J. (1985). American Journal of Physiology 248, R391-R399.

Katz, J. \& Grunnet, N. (1979). In Techniques in Metabolic Research, Part 1, Vol. B208 [H. L. Kornberg, editor].

Katz, J. \& Rognstad, R. (1976). Current Topics in Cellular Regulation 10, 237-289.

McGarry, J. D., Kuwajima, M., Newgard, C. B. \& Foster, D. W. (1987). Annual Review of Nutrition 7, 51-73.

Malloy, C. R., Sherry, A. D. \& Jeffrey, F. M. H. (1987). FEBS Letters 212, 58-62.

Newsholme, E. A. (1978). Biochemical Society Symposia 43, 183-205.

Newsholme, E. A., Challis, R. A. J. \& Crabtree, B. (1984). Trends in Biochemical Sciences 9, 277-280.

Newsholme, E. A. \& Crabtree, B. (1976). Biochemical Society Symposia 41, 61-109.

Newsholme, E. A. \& Leech, A. R. (1983). Biochemistry for the Medical Sciences. Chichester: Wiley \& Sons.

Nicholas, G. A., Lobley, G. E. \& Harris, C. I. (1977). British Journal of Nutrition 38, 1-17.

Nolan, J. V., Norton, B. W. \& Leng, R. A. (1976). British Journal of Nutrition 35, 127-147.

Norwich, K. H. (1977). Molecular Dynamics in Biosystems. Oxford and New York: Pergamon Press.

Pahl-Wostl, C. \& Seelig, J. (1986). Biochemistry 25, 6799-6807.

Pethick, D. W., Lindsay, D. B., Barker, P. J. \& Northrop, A. J. (1981). British Journal of Nutrition 46, 97-110.

Rabkin, M. \& Blum, J. J. (1985). Biochemical Journal 225, 761-786.

Rognstad, R. (1975). Biochemical and Biophysical Research Communications 63, 900-905.

Schulman, G. I., Ladenson, P. W., Wolfe, M. H., Ridgway, E. C. \& Wolfe, R. R. (1985). Journal of Clinical Investigation 76, 757-764. 
Shipley, R. A. \& Clark, R. E. (1972). Tracer Methods for In Vivo Kinetics. New York and London: Academic Press.

Srivastava, D. K. \& Bernhard, S. A. (1986). Science 234, 1081-1086.

Tessari, P., Tsalikian, E., Schwenk, W. F., Nissen, S. L. \& Haymond, M. W. (1985). American Journal of Physiology 249, E121-E130.

Tserng, K.-Y. \& Kalhan, S. C. (1983a). American Journal of Physiology 245, E308-E311.

Tserng, K.-Y. \& Kalhan, S. C. (1983b). American Journal of Physiology 245, E476-E482.

Vinay, P., Mapes, J. P. \& Krebs, H. A. (1978). American Journal of Physiology 234, F123-F129.

Waterlow, J. C., Garlick, P. J. \& Millward, D. J. (1978). Protein Turnover in Mammalian Tissues and in the Whole Body. Amsterdam: Elsevier.

Weinman, E. O., Strisower, E. M. \& Chaikoff, I. L. (1957). Physiological Reviews 37, 252-272.

Williams, J. F., Arora, K. K. \& Longnecker, J. P. (1987). International Journal of Biochemistry 19, $749-817$.

Wiltrout, D. W. \& Satter, L. D. (1972). Journal of Dairy Science 55, 307-317.

Young, J. W., Veenhuizen, J. J. \& Russell, R. W. (1987). Federation Proceedings 46, 295-299. 